\title{
Unusual Occurrence of Paramolar Tubercle on Deciduous Upper First Molar-Report of Two Cases and Literature Review
}

\author{
Mahesh Kumar Duddu ${ }^{1}$, Radhika Muppa ${ }^{1}$, Prameela Bhupatiraju${ }^{1}$, Shefali Waghray ${ }^{2}$, and Vinaya Kumar \\ Kulkarni $^{3}$
}

Departments of ${ }^{1}$ Paedodontics and Preventive Dentistry, ${ }^{2}$ Oral Medicine and Radiology, Panineeya Mahavidhyala Institute of Dental Sciences and Research Centre, Hyderabad, India

${ }^{3}$ Department of Paedodontics and Preventive Dentistry, People's College of Dental Sciences and Research Centre, Bhopal, Madhya Pradesh, India

\section{Article History}

Received 12 October 2011

Accepted 1 May 2012
Keywords :

Paramolar Tubercle, Deciduous

Dentition, Extra cusp

\section{Introduction}

There are various types of dental morphological anomalies, with anomalies of the crown being more common than those of the root. Such anomalies may be found in the form of an extra cusp or tubercle. In 1916, Bolk was the first to describe the formation of an additional cusp on the buccal surfaces of the upper and lower permanent molars (1). In 1925, Leigh reported an enamel tubercle on the maxillary right third molar of an Eskimo skull (2). Extra cusps have subsequently been described by many authors $(3,4,5)$, with forms varying on premolars, molars and incisors. Paramolar tubercle is a term used for an accessory cusp or tubercle located on the buccal surface of premolars and molars (6). The cases presented in this paper highlight the presence of such tubercles on deciduous molars.

Embryologically, these cusps/tubercles are thought to develop from an abnormal proliferation and folding of the inner enamel epithelium and subjacent ectomesenchymal cells of the dental papilla into the stellate reticulum of the

Correspondence to :

Shefali Waghray

E-mail : shefaliwaghray28@gmail.com enamel organ (7). The molecules formed by the primary enamel knot are thought to induce the initiation of secondary enamel knots at the areas of epithelial folding that mark cusp formation in the early bell stage of tooth formation. The resultant cusp morphogenesis and positions appear to form sequentially and cusps that form late in development, after the main cusps, are typically small. The secondary enamel knots disperse after formation of the cusp tips, indicating the termination of crown morphogenesis (7). The paramolar tubercle reported in the present two cases is smaller than the main cusps and may therefore have appeared later in development. The presence of these extra cusps or tubercles may be a cause for dental problems such as caries in the pits and fissures between the tubercle and buccal cusp. Knowledge of these anomalies holds evolutionary importance and also helps in treatment planning for problems associated with such anomalies.

\section{Case Report}

Case 1

A 6-year-old female patient arrived at the Department of Pediatric Dentistry with a chief complaint of decayed teeth 


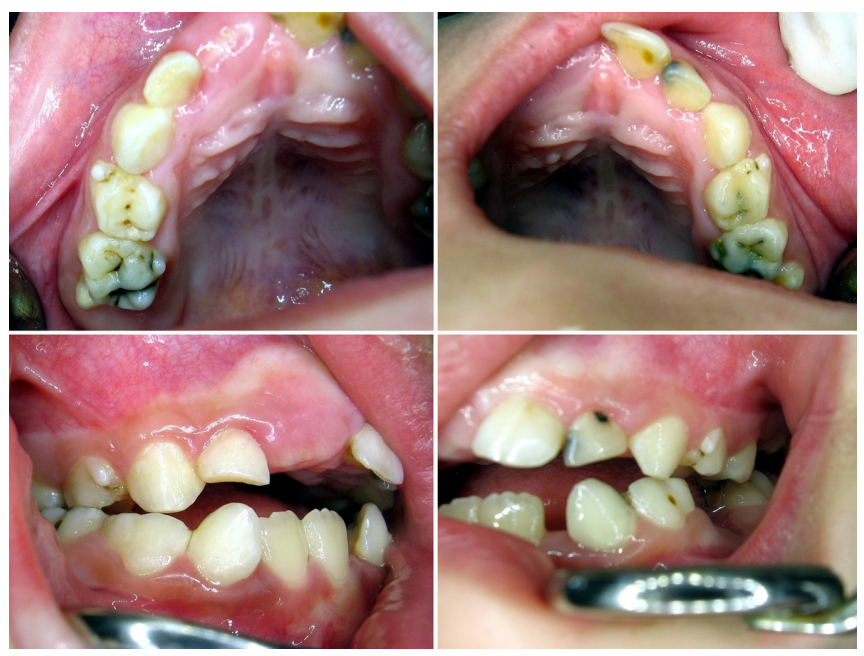

Fig. 1. Paramolar tubercle seen on deciduous maxillary right and left first molars in Case 1.

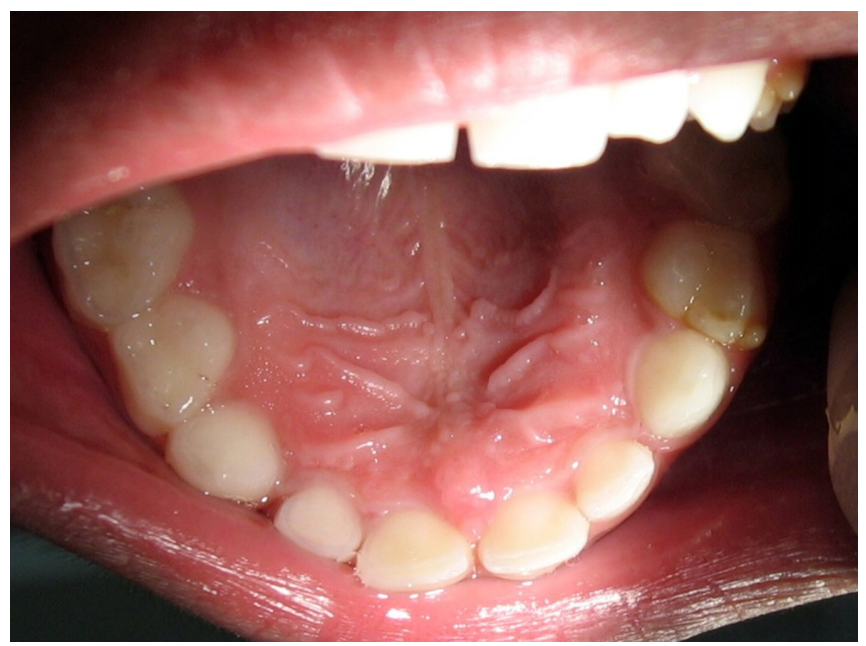

Fig. 2. Paramolar tubercle seen on deciduous maxillary left first molar in Case 2.

in the upper right back region of the jaw and bleeding from gums while brushing. There was no history of pain, and past medical and dental histories were not noteworthy. Intraoral examination revealed a fair oral hygiene status with no evidence of stains or calculus. Hard tissue examination revealed a very interesting morphological variation of the deciduous maxillary right and left first molars. A small tubercle or a cusp-like projection was observed on the buccal surface of both the deciduous maxillary first molars, adjacent to and separated by a groove from the mesiobuccal cusp (Fig.1). Dental caries involving the enamel and dentin were observed in this groove in relation to both the deciduous first molars. No other anatomical structural variations were observed, apart from the cusp of Carabelli,

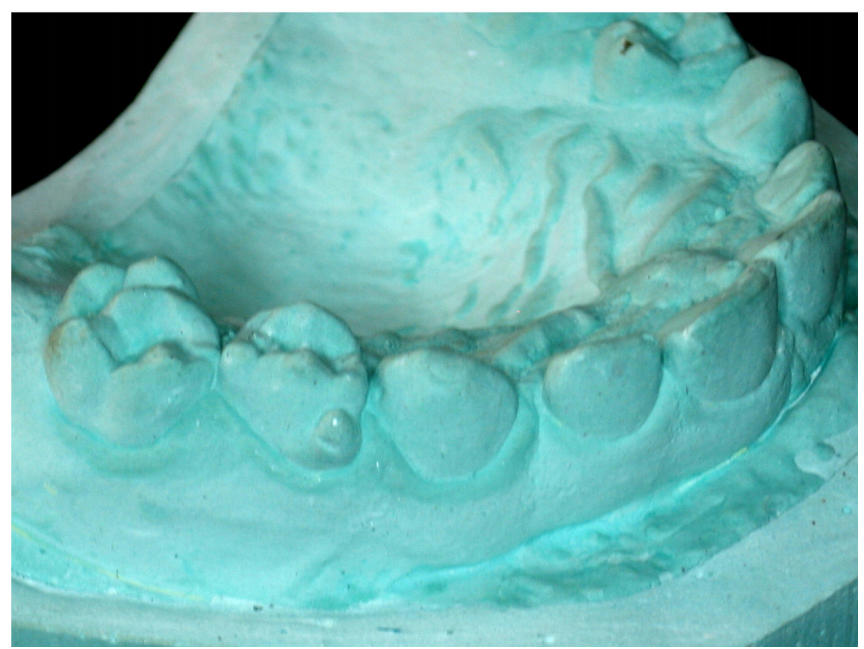

Fig. 3. Paramolar tubercle seen on deciduous maxillary left first molar in Case 2, as represented on a cast.

which was seen on both of the deciduous maxillary second molars. Maxillary and mandibular impressions were made for academic interests.

Case 2

A 5-year-old male patient arrived at the department of pediatric dentistry with a chief complaint of bleeding gums for about 1 month. Past medical and dental histories were not noteworthy. Intraoral examination revealed generalized mild calculus. A small tubercle or cusp-like projection was seen on the buccal surface of the left deciduous maxillary first molar, which was similar to that observed in the previous case (Fig.2). The tubercle was adjacent to and was separated by a groove from the mesio-buccal cusp. An accessory central cusp and a cusp of Carabelli were seen on the deciduous maxillary left second molar. Maxillary and mandibular impressions were made for academic interests (Fig.3).

\section{Discussion}

Accessory cusps or tubercles of the crowns of deciduous teeth are rare. The size, shape and location of these anomalies vary widely and various names have been proposed for such anomalies in the literature. The cusps that were observed in the present cases were located on the buccal surface of the deciduous maxillary first molar and were clearly separated by a groove from the mesio-buccal cusp. A cusp-like projection of this kind seen on permanent teeth has previously been described in literature as the paramolar tubercle (1) and the authors used the same term 
Table 1: Morphological variations on posterior teeth described by Schulge

\begin{tabular}{c|l}
\hline S. No. & Morphological variation \\
\hline 1 & A cone shaped enlargement of lingual cusp \\
\hline 2 & A tubercle on the inclined plane of the lingual cusp \\
\hline 3 & A cone like enlargement of the buccal cusp \\
\hline 4 & A tubercle on the inclines plane of the buccal cusp \\
\hline 5 & A tubercle arising on the occlusal surface obliterating the central groove \\
\hline
\end{tabular}

for describing this structural variation on the deciduous maxillary first molars.

Various names and descriptions have been proposed for extra cusps seen on deciduous molars. Kallay (5) earlier referred to similar projections as protuberantio apulpalis or tuberculum pulpale. Although a well-formed cusp was not described, he noted that deciduous maxillary first molars may have a cone-shaped projection on the mesio-buccal side which is separated from the buccal cusp by a semilunar groove. Wolpoff has referred to large teeth with extra cusps, particularly of the deciduous maxillary first molars, as 'molarized deciduous molars' (8). According to Butler, deciduous first molars are interesting from an evolutionary point of view because of the various degrees of molarization that they show (9). The term 'protostylid' has been used by Dahlberg for a tubercle or an extra cusp found on the buccal side of mesio-buccal cusp of mandibular molars, both deciduous and permanent (10). However, this term is not used for the maxillary molars. Schulge has described five types of morphological variation on the posterior teeth(11) (Table 1). The literature reports very few cases of paramolar tubercle on premolars and molars $(12,13)$, and the authors have not found another case report of a paramolar tubercle on the deciduous maxillary first molar.

\section{Conclusion}

Variations in dental morphology have drawn interest among researchers in terms of evolutionary and genetic studies. This paper highlights two cases with a paramolar tubercle on the deciduous maxillary first molar. It is of interest to note whether a similar variation will appear in the permanent successor or counterpart. The involvement of certain genes in the formation of these cusps in the deciduous and permanent dentition is of particular interest. The cases presented in this paper were followed in order to evaluate whether the permanent dentition would show evidence of similar morphological variations.

\section{References}

1. Bolk L: Problems of human dentition. Am J Anat ,19: 91, 1916.

2. Leigh RW: Dental pathology of the Eskimo. Dent Cosmos, 67: 884-898, 1925.

3. Marvodisz K, Rosza N, Budai M, Soos A, Pap I, Tarjan I: Prevalence of accessory tooth cusps in a contemporary and ancestral Hungarian population. Eur J Orthod, 29:166-169, 2007.

4. Ooshima T, Ishida R, Mishima K, Sobue S: The prevalence of developmental anomalies of teeth and their association with tooth size in the deciduous and permanent dentitions of 1650 Japanese children. Int J Paediatr Dent ,6: 87-94, 1996.

5. Kallay J: Extra cusp formation in the human dentition. J Dent Res ,45:1381-1394, 1966.

6. Kustaloglu OA: Paramolar structures of the upper dentition. J Dent Res, 41: 75-83, 1962.

7. Nirmala S, Challa R, Velpula L, Nuvvula S: Unusual occurrence of accessory central cusp in the maxillary second primary molar. Cont Clin Dent ,2: 127-130, 2011.

8. Wolpoff MH: General anthropology. General Anthropology ,3: 1-16, 1996.

9. Butler PM: Molarization of the first upper deciduous molar. J Dent Assoc S Afr ,43: 503-505, 1988.

10. Dahlberg AA: The paramolar tubercle. Amer J Phys Anthrop, 3: $97-103,1945$.

11. Scott GR, Turner II CG: The Anthropology of Modern Human Teeth. Dental Morphology and its Variations in Recent Human Populations. Cambridge: Cambridge University Press: P 35 -37, 1997.

12. Chiavaro A: Frequency of the supernumerary cusps upon the temporary molars. JADA, 7: 918-923, 1920.

13. Jorgensen KD: The deciduous dentition. Acta Odontol Scandinavica ,14: 72-76, 132-140, 156-158, 1956 (suppl. 20). 